\title{
Determination of Cadmium in River Water Samples by Flame AAS after On-line Preconcentration in Mini-Column Packed with 2-Aminothiazole-modified Silica Gel
}

\author{
Ilton L. AlCântara, ${ }^{* 1}$ Paulo S. Roldan, ${ }^{* 1}$ Gustavo R. CaStro, ${ }^{* 1}$ Fabrício V. Moraes, ${ }^{* 2}$ \\ Fábio A. Silva, ${ }^{* 2}$ Cilene C. F. PAdilha, ${ }^{* 3}$ Jorge D. Oliveira, ${ }^{* 1, * 4}$ and Pedro M. PAdilha ${ }^{*}{ }^{* \dagger}$ \\ *1 Instituto de Química, Departamento de Química Analítica-UNESP, \\ P. O. Box 355, 14800-900, Araraquara, SP, Brasil \\ *2 Instituto de Biociência, Departamento de Química e Bioquímica-UNESP, \\ P. O. Box 510, 18618-000, Botucatu, SP, Brasil \\ *3 Instituto de Biociências, Departamento de Física e Biofísica-UNESP, \\ P. O. Box 510, 18618-000, Botucatu, SP, Brasil \\ *4 Universidade Estadual do Maranhão-CESI, 65901-480, Imperatriz, MA, Brasil
}

\begin{abstract}
A rapid and sensitive method was developed to determine trace levels of $\mathrm{Cd}^{2+}$ ions in an aqueous medium by flame atomic absorption spectrometry, using on-line preconcentration in a mini-column packed with $100 \mathrm{mg}$ of 2-aminothiazol modified silica gel (SiAT). The $\mathrm{Cd}^{2+}$ ions were sorbed at $\mathrm{pH}$ 5.0. The preconcentrated $\mathrm{Cd}^{2+}$ ions were directly eluted from the column to the spectrometer's nebulizer-burner system using $100 \mu \mathrm{L}$ of $2 \mathrm{~mol} \mathrm{~L}^{-1}$ hydrochloric acid. A retention efficiency of over $95 \%$ was achieved. The enrichment factor (calculated as the ratio of slopes of the calibration graphs) obtained with preconcentrations in a mini-column packed with $\operatorname{SiAT}\left(A=-1.3 \times 10^{-3}+1.8 \times 10^{-3}\left[\mathrm{Cd}^{2+}\right]\right)$ and without preconcentrations $\left(A=4 \times 10^{-5}+3.5 \times 10^{-5}\left[\mathrm{Cd}^{2+}\right]\right)$, was 51 and the detection limit calculated was $0.38 \mu \mathrm{g} \mathrm{L}^{-1}$. The preconcentration procedure was applied to determine trace levels of $\mathrm{Cd}$ in river water samples. The optimum preconcentration conditions are discussed herein.
\end{abstract}

(Received February 10, 2004; Accepted April 5, 2004)

Heavy metals (e.g., $\mathrm{Cd}, \mathrm{Cu}, \mathrm{Hg}, \mathrm{Pb})$ at trace levels are proven toxic elements and can be the cause of human health disorders. ${ }^{1,2}$ Because the main sources of these metals for humans are water and food, monitoring the heavy metal content in natural waters is of paramount importance.

The cadmium contamination in environmental samples is generally lower than $5 \mathrm{ng} \mathrm{mL}^{-1}$, so very sensitive techniques are required for determinations. Several analytical techniques exist for determining trace levels of cadmium.,4 Flow injection preconcentration techniques are useful for application in determining heavy metal ions by flame absorption atomic spectrometry (FAAS), providing a superior performance because they allow for the enhancement of sensitivity, separation of the analyte from the matrix and reduction of the risk of contamination. ${ }^{5-8}$ The $\mathrm{Cd}^{2+}$ preconcentration with solid phase extraction (SPE) technique using highly selective sorbentpacked columns has been described elsewhere. ${ }^{9-11}$ Compatible detection limits were obtained by the SPE technique.

In recent years, the use of chemically modified silica gel matrixes with attached groups having a selective affinity for metal ions has been described. ${ }^{12-15}$ A manual procedure with this sorbent-packed column has been proposed for $\mathrm{Cd}$ preconcentration. ${ }^{12,15}$ However, the routine application of this procedure is limited by the time necessary for each analysis (100 min for each determination).

This work describes the analytical performance of a flow

$\doteqdot$ To whom correspondence should be addressed.

E-mail: padilha@ibb.unesp.br injection system with online preconcentration on a sorbent minicolumn packed with 2-aminothiazole-modified silica gel (SiAT) for determining $\mathrm{Cd}$ in a series of river water samples. The material was initially tested with a synthetic aqueous solution containing $\mathrm{Cd}^{2+}$; after that it was used in real samples.

\section{Experimental}

Reagents, analytical solutions and samples

All the solutions were prepared with high purity chemicals and distilled-deionized water (Milli-Q system, Millipore). The hydrochloric and nitric acids used were of the brand Suprapur quality (Merck)

Cadmium standard solutions ( $5-50 \mu \mathrm{g} \mathrm{L}^{-1}$ ) were prepared by stepwise dilution from a $1000 \mathrm{mg} \mathrm{L}^{-1}$ stock solution (Merck Titrisol) with Milli-Q treated water, acidified with nitric acid to $\mathrm{pH} 2$.

The mini-column (a $5 \mathrm{~cm}$ long, $3 \mathrm{~mm}$ i.d. glass tube) was drypacked with $100 \mathrm{mg}$ of SiAT.

Samples of river water (Tietê, Parapanema and Parana rivers, SP, Brazil) were collected and immediately filtered through a $0.45 \mu \mathrm{m}$ membrane. After acidification $(\mathrm{pH}<2.0)$ with $6.0 \mathrm{~mol}$ $\mathrm{L}^{-1} \mathrm{HNO}_{3}$ solution, the samples were stored in highly purified PE containers. Aliquots of $100 \mathrm{~mL}$ of the water samples were digested by oxidation with UV-photolysis in the presence of $0.01 \%$ of $\mathrm{H}_{2} \mathrm{O}_{2}$, using a low-pressure $\mathrm{Hg}$-lamp integrated to a closed quartz vessel. ${ }^{17}$ The aqueous extract resulting was poured into a $100 \mathrm{~mL}$ volumetric flask and this solution was diluted to the final volume with deionized water. 


\section{Synthesis of SiAT}

Silica gel (Merck) with a specific surface area of $500 \mathrm{~m}^{2} \mathrm{~g}^{-1}$ and an average pore diameter of $0.6 \mathrm{~nm}$ was activated at $420 \mathrm{~K}$ under vacuum $\left(10^{-3}\right.$ torr). About $50 \mathrm{~g}$ of this silica was immersed in $200 \mathrm{~mL}$ of purified dimethylformamide (Merck), to which $12 \mathrm{~mL}$ of phosphorus oxychloride (Merck) was added. The mixture was refluxed in a nitrogen atmosphere for $36 \mathrm{~h}$, filtered, washed with dimethylformamide and ethanol and heated under a vacuum to eliminate any remaining solvent. The resulting solid was immersed in $135 \mathrm{ml}$ of purified dimethylformamide and $18 \mathrm{~g}$ of 2-aminothiazole (Aldrich) was added. The mixture was stirred for $26 \mathrm{~h}$ at $380 \mathrm{~K}$ in a nitrogen atmosphere. The resulting modified silica (SiAT) was filtered off, washed with dimethylformamide and ethanol and then heated for $8 \mathrm{~h}$ at $348 \mathrm{~K}$ under a vacuum $\left(10^{-3}\right.$ torr $)$.

Preparation of the SiAT collector can be expressed by Reactions (1) and (2):

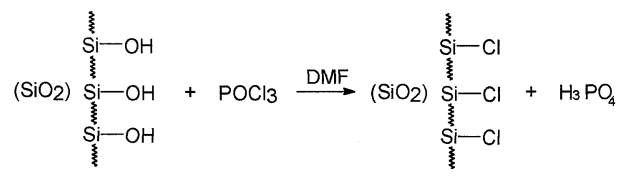

Reaction (1)

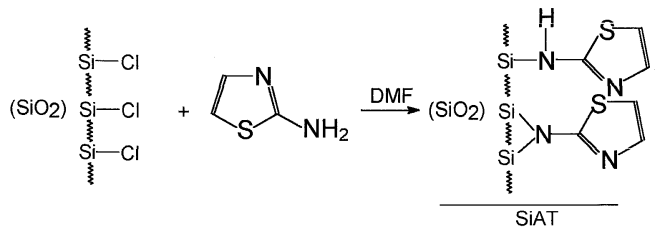

Reaction (2)

The number of 2-aminothiazole groups attached to the silica gel was determined by nitrogen analysis using the Kjeldhal method. The specific surface area was determined by the BET ${ }^{18}$ method using a automated Micromeritics ASAP 2010 device (Micromeritics Instrument Corporation, USA).

\section{Infrared spectra}

Diffuse reflectance infrared Fourier Transform (DRIFT) spectra were obtained in Kubelka-Munk units, using a Nicolet Model Nexus 670 spectrometer equipped with a Smart Collector. One milligram of material was mixed with $500 \mathrm{mg}$ of $\mathrm{KBr}{ }^{19}$

\section{Apparatus}

A SHIMADZU Model AA-6800 atomic absorption spectrometer equipped with a hollow cadmium cathode lamp and a deuterium lamp for background correction was used. The spectrometer's monochromator was adjusted to $228.8 \mathrm{~nm}$ (the resonance line corresponding to a highly cadmium-sensitive wavelength). Several selections were made to adjust the spectrometer, including: slit width, $0.5 \mathrm{~nm}$; burner height, 8 $\mathrm{mm}$; sample uptake rate, $1 \mathrm{~mL} \mathrm{~min}^{-1}$; air flow rate, $2.2 \mathrm{~L} \mathrm{~min}^{-1}$; and acetylene flow rate, $0.9 \mathrm{~L} \mathrm{~min}^{-1}$. The atomic signal was measured in peak height mode.

The on-line preconcentration system was equipped with an Ismatec Model IPC-8 peristaltic pump furnished with Tygon pumping tubes (i.d. $0.5 \mathrm{~mm}$ ) and a homemade Perspex injectorcommutator.

\section{On-line preconcentration system}

Figure 1 shows the flow diagram of the system, which consists of a peristaltic pump, an injection valve (homemade injector-commutator) and a mini-column packed with SiAT.

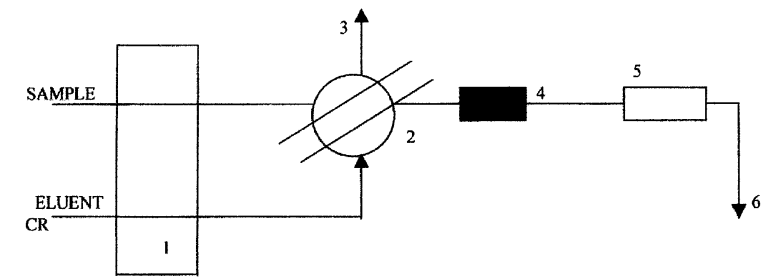

Fig. 1 Flow system for cadmium preconcentration by FAAS: (1) peristaltic pump; (2) injection valve; (3) aqueous waste; (4) minicolumn; (5) FAAS; (6) aqueous waste.

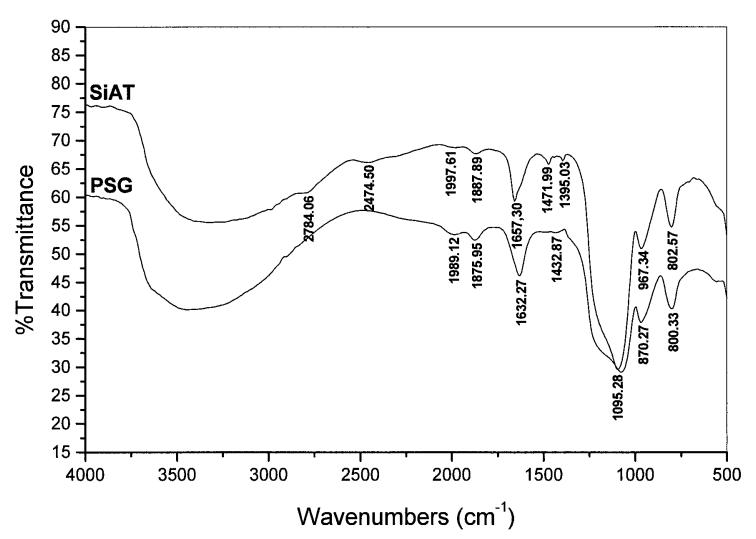

Fig. 2 Infrared spectra of pure silica gel (PSG) and silica gel modified with 2-aminothiazole (SiAT).

Standard solutions (or water samples) in a concentration range of $5-50 \mu \mathrm{g} \mathrm{L}^{-1} \mathrm{Cd}^{2+}$, after being adjusted at convenient $\mathrm{pH}$ with acetate buffer solution, were percolated through a mini-column that adsorbed the $\mathrm{Cd}^{2+}$ ions. The remaining solution was discharged (3-aqueous waste). If one slides the injection valve bar, a stream of water (CR) carries $100 \mu \mathrm{L}$ of a $2.0 \mathrm{~mol} \mathrm{~L}^{-1} \mathrm{HCl}$ solution that desorbs the $\mathrm{Cd}^{2+}$ ions. This eluate was taken directed to the nebulizer-burner system of the spectrometer and the signals were measured as peak heights by using instrument software. The $\mathrm{Cd}^{2+}$ concentrations were read from the analytical curves.

\section{Results and Discussion}

\section{Characteristics of the material}

The infrared SiAT spectra shown in Fig. 2 confirm the presence of 2-aminothiazole groups bound to the silica surface. The small absorption band visible at $2784 \mathrm{~cm}^{-1}$ was due to the $\mathrm{C}-\mathrm{H}$ stretching of aromatic olefins. Two other bands of interest, which are visible at 1471 and $1395 \mathrm{~cm}^{-1}$, were attributed to $\delta \mathrm{C}=\mathrm{N}$ and $\delta \mathrm{N}-\mathrm{H}$, both dislocated from low frequencies due to the remaining $\delta \mathrm{Si}-\mathrm{O}$ in the silica gel, which shows a strong absorption at $1630 \mathrm{~cm}^{-1}$.

The chemical analysis of nitrogen in SiAT revealed that 1.24 $\pm 0.07 \mathrm{mmol} \mathrm{g}^{-1}$ of the functional groups were attached to the silica surface, and that the specific surface area of the SiAT was $354 \pm 0.6 \mathrm{~m}^{2} \mathrm{~g}^{-1}$. The attached 2-aminothiazole groups displayed high stability under the various adsorption-elution cycles of metal ions by the adsorbent in the column.

\section{Effect of physical and chemical parameters}

To adjust the physical and chemical variables for $\mathrm{Cd}^{2+}$ ion preconcentration and elution, we tested the following 


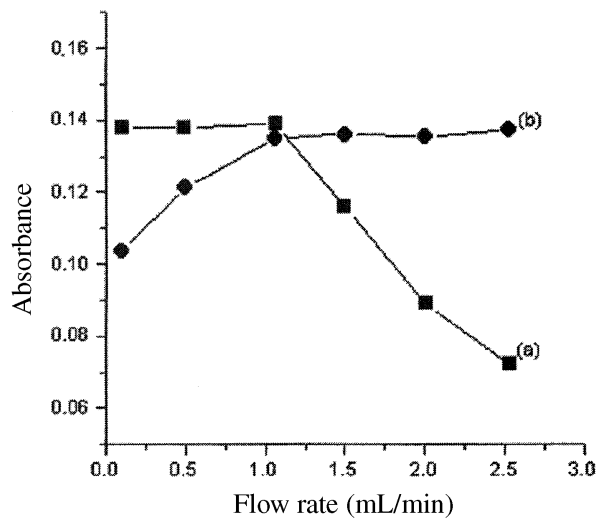

Fig. 3 Effect of flow rate on peak absorbance: a, preconcentration flow rate; $b$, elution flow rate.

parameters were tested.

The preconcentration and elution flow rates were varied from 0.3 to $3 \mathrm{~mL} \mathrm{~min}^{-1}$, while the amount of injected $\mathrm{Cd}^{2+}$ ions was kept at $20 \mu \mathrm{g} \mathrm{L}^{-1}$. As shown in Fig. 3 (graph a), the optimum peak absorbance was obtained at a preconcentration flow rate of about $1 \mathrm{~mL} \mathrm{~min}^{-1}$. The sensitivity increased with increasing elution flow rate (Fig. 3, graph b), reaching the maximum value from $1.5 \mathrm{~mL} \mathrm{~min}^{-1}$ on. Considering the best values of absorbance, the preconcentration and elution flow rates we

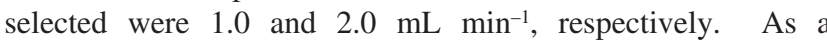
compromise between loading capacities and eluent volumes, different column lengths and inner diameters were tested; the dimensions we selected were $5.5 \mathrm{~cm}$ and $3 \mathrm{~mm}$, respectively.

The effect of $\mathrm{pH}$ on the sorption of $\mathrm{Cd}^{2+}$ in the column's reactive phase was evaluated by varying the $\mathrm{pH}$ in the $1-5$ range with a constant $20 \mu \mathrm{g} \mathrm{L}^{-1}$ injection of $\mathrm{Cd}^{2+}$ solution and a 3 min sampling time (using a flow rate of $1 \mathrm{~mL} \mathrm{~min}^{-1}$ ). These experiments showed that the sorption of $\mathrm{Cd}^{2+}$ ion decreases with the acidity of the solution and that the $\mathrm{pH}$ value 5.0 was optimal for the sorption of $\mathrm{Cd}^{2+}$, results in accordance with these in previous papers. ${ }^{15,16}$ Experiments at $\mathrm{pH}$ values higher than 5 were not carried out because of the possibility of hydrolytic processes and the formation of complexes of type $[\mathrm{Cd}(\mathrm{OH})]^{+}$, that could decrease the transfer of $\mathrm{Cd}^{2+}$ ions from the solution to the SiAT surface. ${ }^{15}$ Thus, the $\mathrm{pH}$ value 5.0 was chosen for further experiments, using $5 \times 10^{-3} \mathrm{~mol} \mathrm{~L}^{-1}$ acetate buffer.

The efficiency of $\mathrm{Cd}^{2+}$ ion elution was investigated using $\mathrm{HNO}_{3}$ and $\mathrm{HCl}$ in varying concentrations. Figure 4 illustrates the influence of eluent concentrations, revealing that the $\mathrm{HCl}$ solutions were more favorable for eluting metal ions. However, elution efficiency increased with increasing $\mathrm{HCl}$ concentrations, remaining constant at about $2.0 \mathrm{~mol} \mathrm{~L}^{-1}$. Therefore, the $2 \mathrm{~mol}$ $\mathrm{L}^{-1} \mathrm{HCl}$ solution was chosen as the eluent.

\section{Analytical performance}

Linear analytical curves were obtained for the $5-50 \mu \mathrm{g} \mathrm{L}-1$ range of $\mathrm{Cd}^{2+}$ preconcentrated using sampling times of 3,4 , and 5 min (volumes injected in triplicate at a flow rate of $1 \mathrm{~mL}$ $\mathrm{min}^{-1}$ ). Accordingly, the calibration slopes increased, but not proportionally with the increase of sampling time, which means that the retention efficiency in not constant.

The enrichment factors, calculated as the ratios of slopes of the calibration graphs obtained with preconcentration in a minicolumn packed with SiAT $\left(A=-1.3 \times 10^{-3}+1.8 \times 10^{-3}\left[\mathrm{Cd}^{2+}\right]\right)$ and without preconcentration $\left(A=4 \times 10^{-5}+3.5 \times 10^{-5}\left[\mathrm{Cd}^{2+}\right]\right)$, were evaluated under the same conditions as described before. Figure 5 shows the calibration graphs obtained for the $5-50 \mu \mathrm{g}$

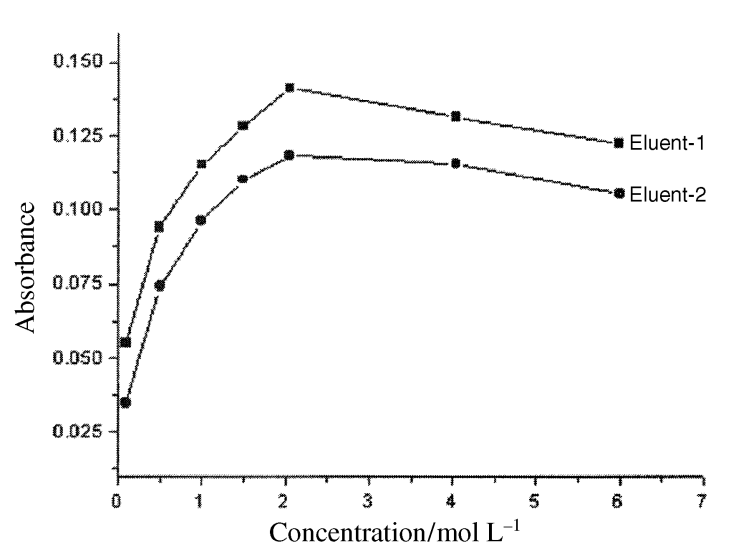

Fig. 4 Influence of eluent concentration on peak absorbance: eluent $1, \mathrm{HCl}$; eluent $2, \mathrm{HNO}_{3}$.

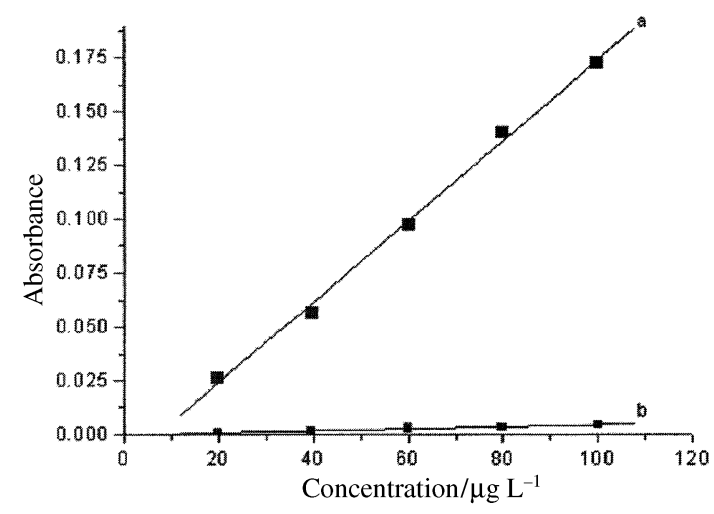

Fig. 5 Calibration graphs: a, with preconcentration in SiAT minicolumn; b, without preconcentration. Experimental conditions: $\mathrm{pH}$, $5.0,2 \mathrm{~mol} \mathrm{~L}^{-1} \mathrm{HCl}$ as eluent; flow rate of eluent, $1.5 \mathrm{~mL} \mathrm{~min} \mathrm{~m}^{-1}$; sampling time, $5 \mathrm{~min}$ at a flow rate of $1.0 \mathrm{~mL} \mathrm{~min}^{-1}$.

$\mathrm{L}^{-1}$ range of $\mathrm{Cd}^{2+}$ preconcentrated for $5 \mathrm{~min}$. The preconcentration factor, which was calculated by comparing it with the calibration graphs without preconcentration (Fig. 5, graph b) and with preconcentration in the SiAT mini-column (Fig. 5, graph a), was 51.

Differences between the preconcentration factor and the added and eluted volumes may have occurred due to loss of efficiency as the sample volumes were increased. As Table 1 indicates, the preconcentration efficiency declined from $99 \%$ to $93 \%$ when sample volumes, gradually increased from 3 to $5 \mathrm{~mL}$, were run through the column. The preconcentration factor under these conditions increased from 29 to 46 . The precision, expressed as RSD for twelve independent determinations, was $3 \%$ for $20 \mu \mathrm{g} \mathrm{L}^{-1}$ of $\mathrm{Cd}^{2+}$ ions. The detection limit, defined as the $\mathrm{Cd}^{2+}$ concentration that gives a response equivalent to three times the standard deviation (SD) of the blank $(n=12),{ }^{20}$ was found to be $0.38 \mu \mathrm{g} \mathrm{L}^{-1}$ for $5 \mathrm{~min}$ of sampling time. The sampling frequency was fifteen samples per hour.

The reproducibility of column preconcentration, expressed as SD and tested by sampling a $20 \mu \mathrm{g} \mathrm{L}^{-1} \mathrm{Cd}^{2+}$ solution for $5 \mathrm{~min}$ in 12 separately prepared mini-columns, was about $99 \pm 3 \%$ $\left(19.80 \pm 0.60 \mu \mathrm{g} \mathrm{L}^{-1}\right)$.

The influence of dissolved salts on the preconcentration of $\mathrm{Cd}^{2+}$ was evaluated by adding $500 \mu \mathrm{g} \mathrm{\textrm {L } ^ { - 1 }}$ of $\mathrm{Cu}^{2+}, \mathrm{Ni}^{2+}$, $\mathrm{Fe}^{3+} / \mathrm{Fe}^{2+}, \mathrm{Pb}^{2+}, \mathrm{Zn}^{2+}, \mathrm{Mn}^{2+}, \mathrm{Cl}^{-}, \mathrm{NO}_{3}{ }^{-}$or $\mathrm{SO}_{4}{ }^{2-}$. The interference study (Table 2) showed that the method proposed is fairly selective for $\mathrm{Cd}^{2+}$. The $\mathrm{Cd}^{2+}$ ions are adsorbed selectively in 
Table 1 Enrichment factors and efficiency of $\mathrm{Cd}^{2+}$ preconcentration mini-column

\begin{tabular}{cccc}
\hline $\begin{array}{c}\text { Sampling time/ } \\
\text { min }\end{array}$ & $\begin{array}{c}\text { Experimental } \\
\text { preconcentration } \\
\text { factor }\end{array}$ & $\begin{array}{c}\text { Theoretical } \\
\text { preconcentration }^{\text {factor }}{ }^{\mathrm{a}}\end{array}$ & $\begin{array}{c}\text { Efficiency, } \\
\%\end{array}$ \\
\hline 3 & 29.7 & 30 & 99 \\
4 & 38.8 & 40 & 97 \\
5 & 46.5 & 50 & 93 \\
\hline
\end{tabular}

Cadmium concentration, $20 \mu \mathrm{g} \mathrm{L} \mathrm{L}^{-1}$; eluent, $100 \mu \mathrm{L}$ of $2 \mathrm{~mol} \mathrm{~L}^{-1} \mathrm{HCl}$

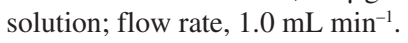

a. Volume added/volume eluted.

Table 2 Effect of foreign ions

\begin{tabular}{lccc}
\hline Ion 500 $\mu \mathrm{g} \mathrm{L}^{-1}$ & Cd recovery, \% & Ion $500 \mu \mathrm{g} \mathrm{L}^{-1}$ & Cd recovery, \% \\
\hline $\mathrm{Cu}(\mathrm{II})$ & $98 \pm 3$ & $\mathrm{Cr}(\mathrm{III})$ & $97 \pm 5$ \\
$\mathrm{Ni}(\mathrm{II})$ & $96 \pm 4$ & $\mathrm{Cl}^{-}$ & $98 \pm 6$ \\
$\mathrm{Fe}(\mathrm{III}) / \mathrm{Fe}(\mathrm{II})$ & $94 \pm 4$ & $\mathrm{NO}_{3}{ }^{-}$ & $97 \pm 4$ \\
$\mathrm{~Pb}(\mathrm{II})$ & $98 \pm 3$ & $\mathrm{SO}_{4}{ }^{2-}$ & $96 \pm 5$ \\
$\mathrm{Zn}(\mathrm{II})$ & $97 \pm 5$ & $\mathrm{PO}_{4}{ }^{3-}$ & $92 \pm 5$ \\
$\mathrm{Mn}(\mathrm{II})$ & $99 \pm 4$ & & \\
\hline
\end{tabular}

$20 \mu \mathrm{g} \mathrm{L}{ }^{-1}$ of $\mathrm{Cd}(\mathrm{II}), 5$ min sampling time.

SiAT-packed columns because of the strong affinity of $\mathrm{Cd}^{2+}$ ions for the thiazole groups of SiAT. This behavior is congruent with Pearson's classification of hard and soft acids and bases, ${ }^{21}$ according to which soft acids $\left(\mathrm{Cd}^{2+}\right)$ bind preferentially to soft bases (thiazole groups, in this case).

\section{Determination of cadmium in river water samples}

The method proposed here was successfully applied to determine cadmium in samples of river water from various sources (Tietê, Parapanema and Parana rivers, SP, Brazil, which are contaminated by heavy metals). Table 3 lists the results obtained through the proposed method. As Table 3 indicates, the SiAT-FAAS determinations revealed cadmium concentrations $16-25 \%$ lower in undigested river water samples than in the photolyzed samples. This difference in results has been attributed to the formation of inert complexes of $\mathrm{Cd}$ with aquatic humic substances (HS), which are less accessible for the functional groups of the collector. ${ }^{22}$ After digestion (by oxidizing UV-photolysis in the presence of $0.01 \%$ $\mathrm{H}_{2} \mathrm{O}_{2}$ ), the $\mathrm{Cd}^{2+}$ ions bound to HS in the form of inert complexes can react quantitatively with functional SiAT groups. These findings are congruous with results obtained by direct determination through GFAAS (graphite furnace absorption atomic spectrometry), also listed in Table 3.

\section{Conclusions}

The method proposed represents a good alternative for determining cadmium at ultra low trace levels in an aqueous medium. The high stability of the SiAT-packed mini-column is evidenced by life times of at least one year if unused and at least one month if used $5 \mathrm{~h}$ per day. The proposed method allows for online cadmium determination in natural water samples by FAAS, although it requires predigestion of samples, e.g., by a sample oxidizing UV photolysis, which is necessary to eliminate the interference of aquatic organic matter, particularly aquatic humic substances that can form inert complexes with $\mathrm{Cd}^{2+}$ ions.
Table 3 Determination of $\mathrm{Cd}$ in different water samples by FAAS with on-line preconcentration in a SiAT-packed minicolumn with and without digestion by UV-photolysis $\left(\mu \mathrm{g} \mathrm{L}^{-1}\right)$

\begin{tabular}{ccccc}
\hline Sample & \multicolumn{2}{c}{ GFAAS } & \multicolumn{2}{c}{ SiAT-FAAS } \\
\hline 1 & $14 \pm 3^{\mathrm{a}}$ & $10 \pm 2$ & $12 \pm 3^{\mathrm{a}}$ & $9 \pm 0.27$ \\
2 & $9 \pm 0.3^{\mathrm{a}}$ & $7 \pm 0.2$ & $10 \pm 2^{\mathrm{a}}$ & $8 \pm 0.24$ \\
3 & $5 \pm 0.15^{\mathrm{a}}$ & $4 \pm 0.12$ & $6 \pm 0.18^{\mathrm{a}}$ & $5 \pm 0.15$ \\
\hline
\end{tabular}

1, Tiete river; 2, Parapanema river; 3 , Parana river.

a. Photolyzed water samples.

\section{Acknowledgements}

The authors thank the Brazilian institutions FAPESP (Project 99/12916-0) and FUNDIBIO for their financial support of this research we thank CAPES and CNPq for the fellowships granted to J. D. Oliveira, I. L. Alcântara, P. S. Roldan and G. R. Castro.

\section{References}

1. A. Taylor, Clin. Endocrinol Metabolism, 1985, 14, 662.

2. R. D. Wilken, Fresenius J. Anal. Chem., 1992, 342, 795.

3. C. J. Rademeyer, B. Radziuk, N. Romanova, N. P. Skaugset, A. Skogstad, and Y. J. Thomassen, Anal. At. Spectrom., 1995, 10, 739.

4. E. C. Lima, F. J. Krug, and K. W. Jackson, Spectrochim. Acta, Part B, 1998, 53, 1791.

5. Z. Fang, "Flow Injection Separation and Preconcentration", 1993, John Wiley and Sons, New York, 146.

6. R. A. Nickson, S. J. Hill, and P. J. Worsfold, Anal. Proc. Incl. Anal. Comp., 1995, 32, 387.

7. P. C. Ruder, A. G. Torres, J. M. C. Pavón, and F. S. Rojas, Talanta, 1998, 46, 1095.

8. J. C. Rocha, J. J. Sene, P. Burba, and D. Klockow, J. Braz. Chem. Soc., 1998, 9, 79.

9. M. Sperling, X. Yin, and B. Welz, J. Anal. At. Spectrom., 1990, 5, 639.

10. P. M. Padilha, J. C. Rocha, J. T. S. Campos, J. C. Moreira, and C. C. Federici, J. Braz. Chem. Soc., 1997, 8, 333.

11. P. M. Padilha, J. C. Rocha, J. T. S. Campos, J. C. Moreira, and C. C. Federici, Talanta, 1997, 45, 317.

12. N. L. D. Filho, Y. Gushikem, W. L. Polito, J. C. Moreira, and E. O. Ehrim, Talanta, 1995, 42, 1625.

13. P. Lessi, N. L. D. Filho, J. C. Moreira, and J. T. S. Campos, Anal. Chim. Acta, 1996, 306, 175.

14. L. A. M. Gomes, P. M. Padilha, J. C. Moreira, N. L. D. Filho, and Y. Gushikem, J. Bras. Chem. Soc., 1998, 9, 494.

15. P. M. Padilha, L. A. M. Gomes, C. C. F. Padilha, J. C. Moreira, and N. L. D. Filho, Anal. Lett., 1999, 32, 1807.

16. F. V. Moraes, G. R. Castro, I. L. Alcântara, P. S. Roldan, M. A. L. Margionte, and P. M. Padilha. Ecl. Quím., 2003, 28(1), 9.

17. P. Burba and R. E. Wilmer, Fresenius J. Anal. Chem., 1992, 324, 167.

18. S. Brunaur, P. Emmet, and E. Teller, J. Am. Chem. Soc., 1938, 60, 309.

19. Y. Gushikem and J. C. Moreira, J. Colloid Interface Sci., 1985, 13, 70 .

20. K. Zih-Perényi, A. Lásztity, Zs. Horváth, and A. Lévai, Talanta, 1998, 47, 673.

21. R. G. Pearson, J. Am. Chem. Soc., 1963, 85(22), 3533.

22. J. C. Rocha, I. A. S. Toscano, and P. Burba, Talanta, 1997, $44,69$. 